\title{
AMINOHYDROLASES ACTING ON ADENINE, ADENOSINE AND THEIR DERIVATIVES
}

\author{
Hana Pospisilova, Ivo Frebort
}

\author{
Department of Biochemistry, Faculty of Science, Palacky University, Slechtitelu 11, 78371 Olomouc, Czech Republic \\ e-mail: h.pospisilova@upol.cz
}

Received: January 20, 2007; Accepted: May 15, 2007

Key words: Adenine deaminase/Adenase/Adenosine deaminase/Aminohydrolase/Gene organization/Protein structure

Background: Adenine and adenosine-acting aminohydrolases are important groups of enzymes responsible for the metabolic salvage of purine compounds. Several subclasses of these enzymes have been described and given current knowledge of the full genome sequences of many organisms, it is possible to identify genes encoding these enzymes and group them according to their primary structure.

Methods and Results: This article is a short overview of the enzymes classified as adenine and adenosine deaminase. It summarises knowledge of their occurrence, genetic basis and their catalytic and structural properties.

Conclusions: These enzymes are constitutive components of purine metabolism and their impairment may cause serious medical disorders. In humans, adenosine deaminase deficiency is linked to severe combined immunodeficiency and as such the enzyme has been approved for the first gene therapy trial. The role of these enzymes in plants is unclear, since the activity was has not been detected in extracts and putative genes have not been yet cloned and analyzed. A literature search and amino acid identity comparison show that Ascomycetes contain only adenine deaminase, but not adenosine deaminase, despite the fact that corresponding genes are annotated in databases as the adenosine cleaving enzymes because they share the same conserved domain.

\section{INTRODUCTION}

Out of 44 enzymes systematically labelled as aminohydrolases in the Enzyme Commission, 25 are classified as deaminases. These enzymes control important pathways in the metabolism of the components of nucleic acids ${ }^{1}$, Fig. 1A. Genetic deficiency in these pathways in humans results in serious diseases, such as severe combined immunodeficiency caused by diminished activity of adenosine deaminase. Six of the known deaminases are involved in the salvage of adenine and its derivatives and nitrogen catabolism. This review focuses on the enzymes adenine deaminase and adenosine deaminase and covers recent progress in understanding their genetic origin and biochemical properties.

\section{ADENINE DEAMINASE}

Adenine deaminase (alternatively also adenine aminohydrolase or adenase, ADE, EC 3.5.4.2) catalyzes the hydrolytic cleavage of adenine to produce hypoxanthine and ammonia (Fig. 1B). ADE genes have been found in prokaryotes and lower eukaryotes such as yeasts or protozoa. Until recently, genes coding eukaryotic adenine deaminase were unknown, but genetic and physiological evidence indicated that these enzymes are present in Ascomycetes. Surprisingly, when some putative fungal adenosine deaminases (ADA, EC 3.5.4.4) have been cloned and expressed in E. coli, they exhibited adenine deaminase activity ${ }^{2}$. At the amino acid sequence level, bacterial adenine deaminases are more closely related to allantoinases, ureases and dihydroorotases than to fungal enzymes $^{2}$. Of this enzyme class, a structure of bacterial ADE from Enterococcus faecalis has been the first and so far the only one to become available ${ }^{3}$ (in October 2006), Fig. 2A.

\subsection{Substrates, activating compounds and inhibitors of adenine deaminase}

Adenine deaminases have been detected in different microorganisms, such as Pseudomonas synxanth ${ }^{4}$, Bacillus subtilis $^{5}$, Leishmania donovani ${ }^{6}$, E. coli ${ }^{7}$ and Azotobacter vinelandil ${ }^{8}$. Some of the enzymes were partially purified and characterized in terms of specific activity and $K_{\mathrm{m}}$ value. The enzymatic activity showed a maximum between pH 6 (C. fasciculata $\left.^{9}\right)$ and $\mathrm{pH} 9\left(\right.$ P. synxantha $\left.{ }^{10}\right)$. Optimal temperature was found to be diverse, i.e. $40-45{ }^{\circ} \mathrm{C}$ for ADE from $P$. synxantha, but $60{ }^{\circ} \mathrm{C}\left(\right.$ ref. $\left.^{7}\right)$ for the $E$. coli enzyme. Genes coding for ADE from E. coli ${ }^{7}, S$. cerevisiae ${ }^{11}$ and B. subtilis ${ }^{5,12}$ have been cloned and overexpressed in modified E. coli.

The only natural substrate of ADE is adenine ${ }^{13}$, but the enzyme can also hydrolyze 6-halogenpurines ${ }^{4,14}$ such as 6-chloropurine. Metal ions in optimum concentration are essential for the enzymatic activity of some enzymes, i.e. $\mathrm{Mn}^{2+}$ for the ADEs from Bacillus subtilis ${ }^{5}$ and Escherichia coli ${ }^{7}$. In contrast, many ions act as partial or full inhibitors of $\mathrm{ADEs}^{4,7,8}\left(\mathrm{Ca}^{2+}, \mathrm{Cd}^{2+}, \mathrm{Co}^{2+}, \mathrm{Cu}^{2+}, \mathrm{Fe}^{2+}, \mathrm{Hg}^{2+}, \mathrm{Ni}^{2+}\right.$, $\mathrm{Zn}^{2+}$ and $\mathrm{Mn}^{2+}$. Metal chelators, such as 1,10-phenanthroline $^{10}, p$-chloromercuribenzoate ${ }^{4}$, mercuric acetate, mercuric chloride, iodoacetic acid, $\mathrm{NaCN}, \mathrm{NaF}$, and $\mathrm{NaN}_{3}{ }^{4}$ 
Table 1. Comparison of amino acid identity of bacterial and fungal ADEs with some prokaryotic and eukaryotic ADAs. Data were obtained using ClustalW multiple sequence alignment followed by sequence identity matrix calculation using the BioEdit software 7.0.5.360.

Gene identification: 1. cryptic ADE Escherichia coli K12 (yicP), GeneID: 948210, 2. ADE Methanosarcina acetivorans C2A, GeneID: 1474199, 3. ADE Schizosaccharomyces pombe 972h-, GeneID: 2540066, 4. putative ADE Candida albicans SC5314, GeneID: 3643529, 5. ADE Saccharomyces cerevisiae, GeneID: $855581, \mathbf{6}$. ADA Homo sapiens, GeneID: 100, 7. ADA Schizosaccharomyces pombe $972 \mathrm{~h}-$, GeneID: $2540165, \mathbf{8}$. ADA Leishmania major strain Friedlin, GeneID: 3684336, 9. ADA Aspergillus fumigatus Af293, GeneID: 3513729, 10. ADA Mesorhizobium loti MAFF303099, GeneID: 1226989, 11. ADA Escherichia coli K12, GeneID: 945851

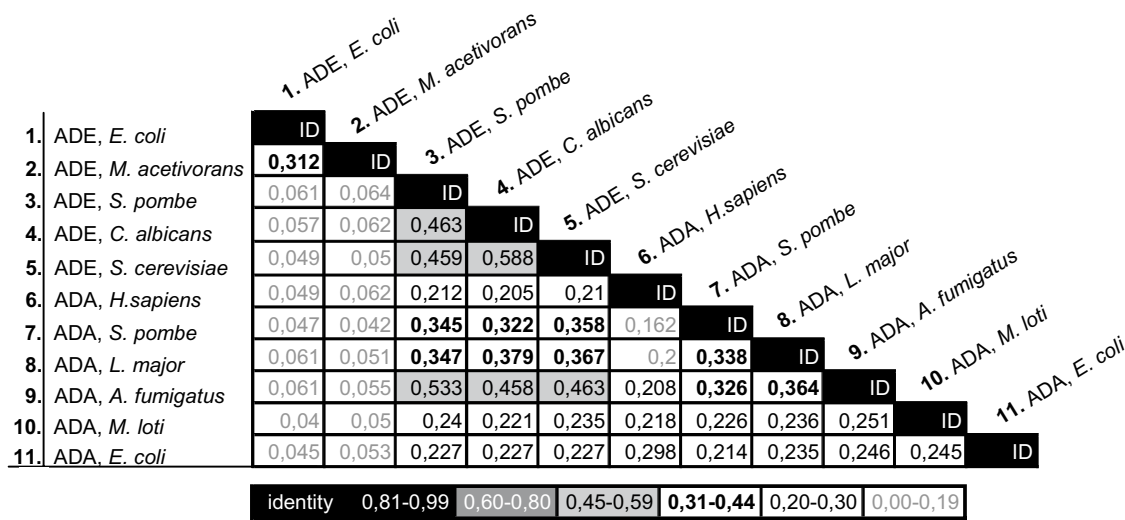

Table 2: Comparison of amino acid identity among prokaryotic and eukaryotic ADAs. Data were obtained using ClustalW multiple sequence alignment followed by sequence identity matrix calculation using the BioEdit software 7.0.5.3.

Gene identification: 1. ADA Homo sapiens, GeneID: 100, 2. ADA Pan troglodytes, GeneID: 741760, 3. ADA Bos taurus, GeneID: 280712, 4. ADA Canis familiaris isoform 1, GeneID: 477236, 5. ADA Mus musculus, GeneID: 11486, 6. ADA Rattus norvegicus, GeneID: 24165, 7. ADA Gallus gallus, GeneID: 419194, 8. ADA Xenopus tropicalis, GeneID: 496434, 9. ADA Danio rerio, GeneID: 436919, 10. ADA Schizosaccharomyces pombe 972h-, GeneID: 2540165, 11. ADA Leishmania major strain Friedlin, GeneID: 3684336, 12. ADA Plasmodium berghei strain ANKA, GeneID: 3425563, 13. ADA Aspergillus fumigatus Af293, GeneID: 3513729, 14. ADA Escherichia coli K12, GeneID: 945851, 15. ADA Vibrio cholerae O1 biovar eltor str. N16961, GeneID: 2614914.

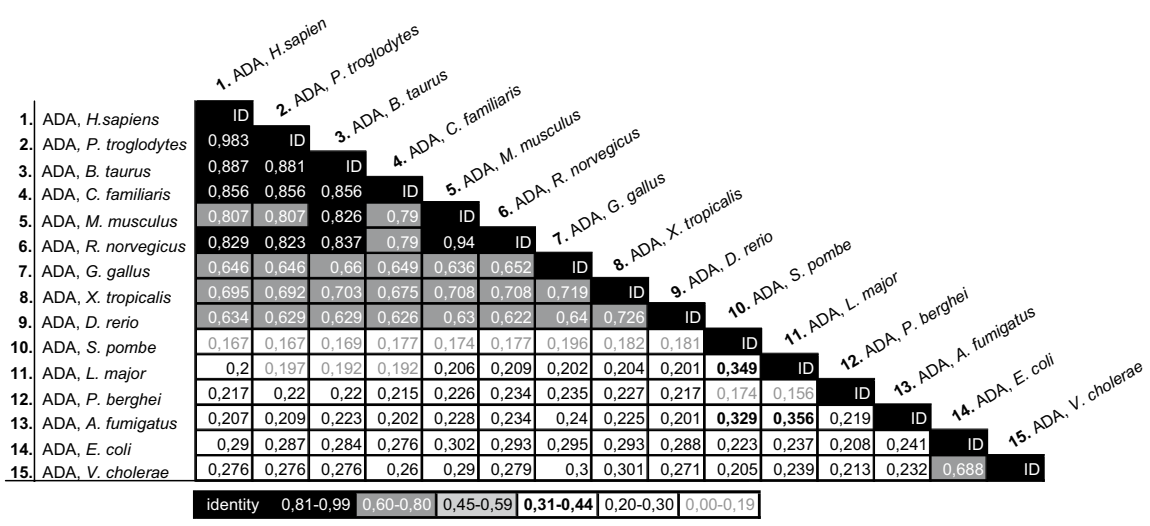

Table 3. Comparison of amino acid identity between putative plant adenosine/AMP deaminases and the enzymes from other organisms containing the same conserved domain cd00443. Data were obtained using ClustalW multi-

ple sequence alignment followed by sequence identity matrix calculation using the BioEdit software 7.0.5.360.

Gene identification: 1. ADA/AMPD Arabidopsis thaliana, GeneID: 825826, 2. ADA/AMPD Oryza sativa (japonica cultivar-group), GeneID: 4344179, 3. ADA/AMPD Homo sapiens GeneID: 161823, 4. ADA/AMPD Bos taurus, GeneID: 512667, 5. ADA/AMPD Danio rerio GeneID: 619263, 6. ADA/AMPD Anopheles gambiae str. PEST, GeneID: 1274840, 7. ADA/AMPD Ustilago maydis 521, GeneID: 3628643, 8. ADA/AMPD Gibberella zeae PH-1 GeneID: 2784988, 9. ADA/AMPD Aspergillus nidulans FGSC A4, GeneID: 2876437, 10. ADA/AMPD Aspergillus terreus NIH2624, GeneID: 4355279, 11. ADA/AMPD Synechococcus elongatus PCC 6301, GeneID: 3198705.

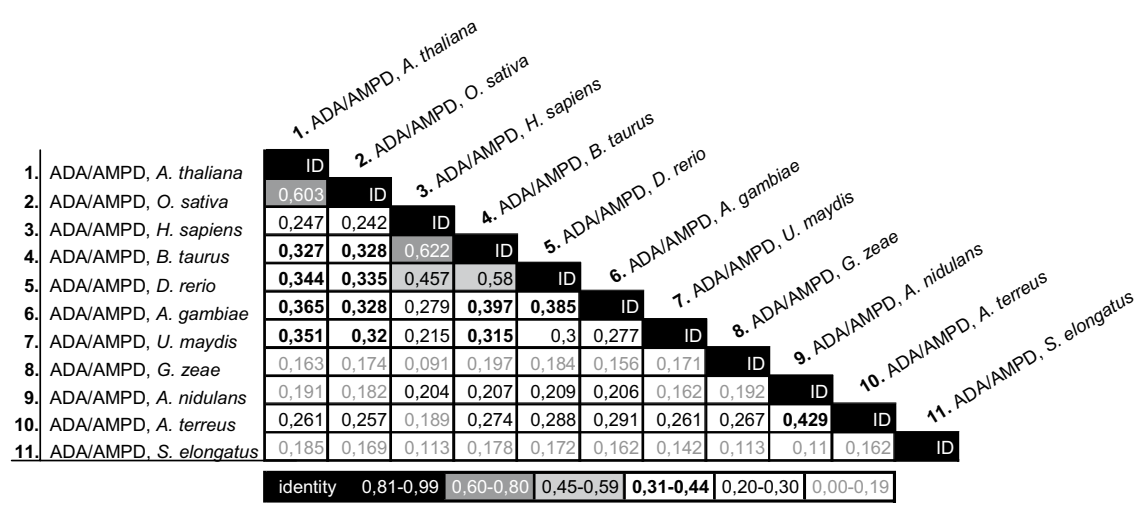


also inhibit adenine deaminases. Other inhibitors of these enzymes are mostly substrate analogs, such as purine ${ }^{9}$, coformycin and its derivatives ${ }^{6}, 6$-methyl- and dimethylaminopurine $^{4}$, hypoxanthine ${ }^{9}$, and 4-aminopyrazolo $[3,4-d]$ pyrimidine ${ }^{4}$.

\subsection{Genetic relationship of adenine deaminases}

Protein BLAST results of prokaryotic and eukaryotic ADEs clearly show that fungal enzymes are only weakly similar to bacterial and archaeal ones (Tab. 1). Differences between archaeal and bacterial ADEs themselves are moderate, suggesting that they have close genetic origin as shown by phylogenetic analysis (Fig. 3A). These prokaryotic proteins form a separate group that is clearly distinct from any other ADE or ADA enzymes as indicated by low degree of amino acid sequence identity. Known eukaryotic ADE enzymes share a very high degree of similarity with putative fungal ADAs and they also contain conserved amino acid domains that associate them with bacterial and mammalian ADAs as well.

\subsection{Protein structure of adenine deaminase}

The enzyme AAH1 from Saccharomyces cerevisiae is a typical representative of ADEs from lower eukaryotes. The gene coding for this protein (GeneID: 855581) is located on chromosome XIV (NC_001146) at the position form 359598 to 360641 (1043 bp) and has no introns. According to amino acid domain search, the enzyme belongs to the metal-dependent hydrolase superfamily, adenosine deaminase (ADA) family and more specifically to the sub-family of $\alpha / \beta$ barrel enzymes, adenine deaminase family 2 . The main structural feature of this protein is the conserved domain cd01320 that is characteristic for a monomeric zinc-dependent protein, which catalyzes the irreversible hydrolytic deamination of both adenosine, as well as 2 -deoxyadenosine, to ammonia and inosine or deoxyinosine, respectively. The same domain is present in the majority of adenosine deaminases.

A typical representative of bacterial ADEs is a yicP cryptic adenine deaminase from $E$. coli $\mathrm{K} 12$. The encoding gene (GeneID: 945851) is localized on the genome at the position from 3841987 to 3843753 (1766 bp). The enzyme belongs to the same superfamily, adenine deaminase family $1^{2}$ and contains the conserved domain cd01295 (AdeC: adenine deaminase directly deaminating adenine to form hypoxanthine), which is different from the cd01320 domain of AAH1. Similar domain architecture is found for the enzyme from Enterococcus faecalis, the structure of which has been solved recently (Fig. 2A).

\section{ADENOSINE DEAMINASE}

Adenosine deaminase (alternatively also adenosine aminohydrolase, ADA, EC 3.5.4.4) catalyzes irreversible deamination of adenosine and 2'-deoxyadenosine to inosine and deoxyinosine. This kind of enzyme is present in prokaryotic and eukaryotic organisms in different forms and belongs to the family of $\alpha / \beta$ barrel enzymes ${ }^{2}$ similarly to the adenine deaminases. Given their widespread occurrence and importance in the medical field, these enzymes have been investigated more profoundly than adenine deaminases. ADA is found in a variety of prokaryotes and eukaryotes (insects, lower vertebrates, fish, mammals and possibly also in plants).

In prokaryotes and eukaryotes, proteins that exhibit adenosine deaminase activity include not only the classical ADA (EC 3.5.4.4), but also ADA regulatory proteins (only in prokaryotes) with different conserved domains (EC 2.1.1.63) and tRNA-specific adenosine deaminases (ADATs), which are structurally very similar to ADAs. ADAT was the first prokaryotic RNA editing enzyme to be identified in $E$. coli $i^{15}$. As described above, fungal ADEs are very similar at the amino acid sequence level to microbial ADAs and for this reason if classified solely on sequence homology could be easily mistaken.

\subsection{Mammalian adenosine deaminase}

Two different isoenzymes ${ }^{16}$ of ADA, ADA1 and ADA2, found in higher eukaryotes are encoded by different genes ${ }^{17}$. In humans, almost all ADA activity is attributed to a single-chain $\mathrm{Zn}$-binding protein ADA1, whereas ADA2 is found in negligible quantities in serum and may be produced by monocytes/macrophages ${ }^{18}$. ADA1 is expressed in all human tissues, its activity levels being relatively high in thymus and duodenum (about $10 \mathrm{nkat} / \mathrm{mg}$ ), whereas more than 500-fold lower activity was reported in liver ${ }^{19}$. The molecular basis for tissue-specific expression of ADA has been studied by analyzing ADA1 gene promoter and interactions of nuclear proteins with enhancer elements ${ }^{20}$. Specific regulatory regions of the gene coding for ADA1 in humans were investigated in transgenic experiments using ADA1 gene and promoter fragments linked to a bacterial chloramphenicol acetyl transferase (CAT) reporter gene ${ }^{20}$. A 232-bp region $(-211$ to +11) from the ADA1 gene promoter confers high basal reporter gene (CAT) expression in transient transfection assays in mammalian cells ${ }^{21,22}$.

Mutations in the ADA1 gene that block its expression cause severe combined immunodeficiency, whereas mutations leading to overexpression cause hemolytic anemia. Lack of ADA1 activity leads to an accumulation of dATP that causes inhibition of the ribonucleotide diphosphate reductase activity, the enzyme that synthesizes DNA and RNA which are required in a large amount during lymphocyte proliferation. There is also some evidence that the other different allelle (ADA2) may lead to autism.

Recently, ADA2 has been identified as a member of a new class of ADGFs (ADA-related growth factors), which is present in almost all organisms ${ }^{18}$.

Two additional types of adenosine deaminase are found in higher eukaryotes, ADATs and ADARs. Adenosine deaminase acting on RNA (ADAR) has the ability to deaminate adenosines in any long double-stranded RNA and converting them to inosines. ADARs are commonly found in animals, but not known in other organisms. ADARs are presumed to evolve from the adenosine deaminases acting on tRNAs (ADATs), by steps including fusion of two or more double-stranded-RNA binding domains to a common type of zinc-containing adenosinedeaminase domain ${ }^{23}$. 


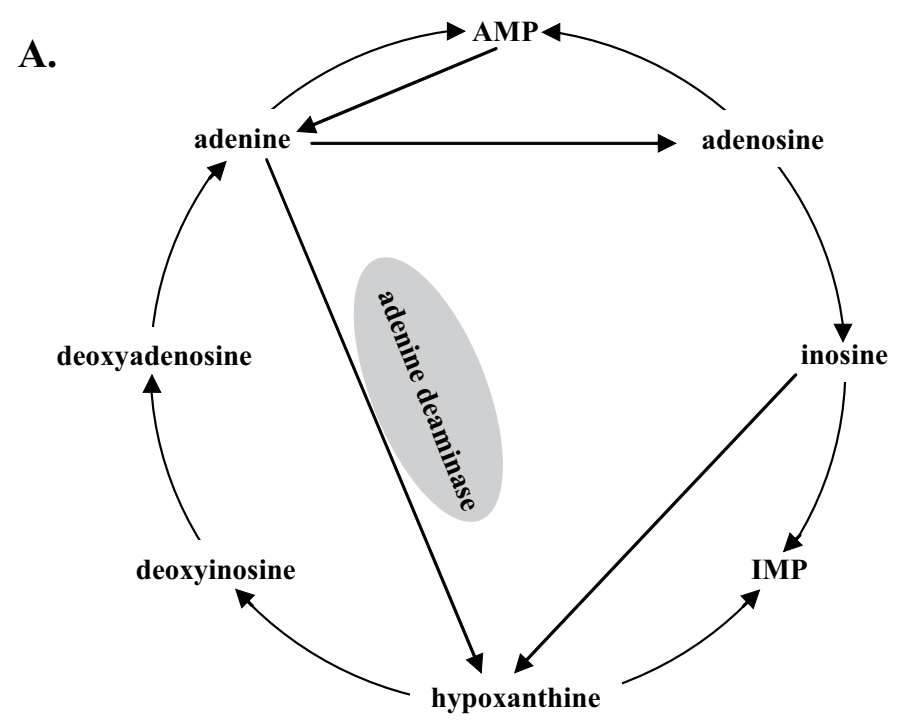

B.<smiles>Nc1ncnc2[nH]c(C(C(=O)O)C(F)(F)F)nc12</smiles>

Fig. 1. Adenine deaminase (ADE, EC 3.5.4.2): A. Role of ADE in salvage pathways of adenine, hypoxanthine and their nucleosides (Saccharomyces cerevisiae), B. Catalytic reaction of ADE.

\subsection{Substrates, activating compounds and inhibitors of adenosine deaminase}

Substrates of different adenosine deaminase enzymes are adenosine ${ }^{24}$ and adenine $e^{25}$ and their derivatives, such as 2', 3'-deoxyadenosine ${ }^{26}, 2^{\prime}$-deoxyadenosine ${ }^{27}, 3^{\prime}$ deoxyadenosine ${ }^{25}$, isopropylideneadenosine ${ }^{28}$, adenine arabinoside ${ }^{29}, 2^{\prime}$-dAMP ${ }^{30}, 5^{\prime}$-AMP ${ }^{31}$, adenosine-3'-monophosphate $^{32}$, ADP and $\mathrm{ATP}^{31}, \mathrm{cAMP}^{32}$, double-stranded $\mathrm{RNA}^{33}$, tRNA ${ }^{34}$, and other purine compounds as 2-amino-6-chloropurine riboside ${ }^{28}, 6$-chloropurine riboside and 6-methoxypurinriboside ${ }^{35}$, 6-methylaminopurine ribonucleoside ${ }^{25}$, and formycin $\mathrm{A}^{27}$.

Metals ions in specific concentrations are in some cases essential for the activity. $\mathrm{MgCl}_{2}$ and $\mathrm{CoSO}_{4}$ had a remarkable activating effect on ADA from Aspergillus terricola ${ }^{36} . \mathrm{Fe}^{3+}$ or $\mathrm{Sn}^{2+}$ are promoting the enzymatic reaction of Nocardioides sp. J-326 $\mathrm{TK}^{31}$ and Streptomyces sp. $^{32}$ adenosine deaminases. For Bacillus cereus enzyme, the activity is stabilized by $\mathrm{NH}_{4}^{+}$or $\mathrm{K}^{+}$, while it is irreversibly lost in the absence of these or a few other monovalent cations ${ }^{37}$. Activating compounds were also described for the enzymes from Argopecten irradians concentricus $\left(\mathrm{NH}_{4} \mathrm{Cl},\left(\mathrm{NH}_{4}\right)_{2} \mathrm{SO}_{4}\right)^{38}$, Candida albicans enzyme (8-aza-adenine, adenine, AMP, ATP, IMP, inosine, $N$-acetyl-D-glucosamine $)^{39}$ and Mus musculus (dibutyryl-cAMP) $)^{40}$.

The value of $\mathrm{pH}$ optimum significantly varies among enzymes from different sources, but usually confines to the range between $\mathrm{pH} 5$ and 8 . The $\mathrm{pH}$ range to observe enzymatic activity was shown to be $\mathrm{pH}$ 5-9 for Bos taurus $\mathrm{ADA}^{41}, \mathrm{pH}$ 4-8 for Candida albicans ${ }^{39}$ and $\mathrm{pH}$ 3.5-5.5 for Streptomyces $\mathrm{sp} .{ }^{32}$ enzyme. Temperature optimum ranges from $25^{\circ} \mathrm{C}$ for ADA from camel (Camelus dromedaries) ${ }^{42}$ to $55^{\circ} \mathrm{C}$ for the one from Streptomyces $\mathrm{sp}^{32}$.

Wide spectrum of inhibitors has been described for adenosine deaminases. Aspergillus terricola enzyme is inhibited by the 2-mercaptoethanol, iodoacetic acid, $\mathrm{Mn}^{2+}$, reduced glutathione and by EDTA, which indicates that this ADA is a metaloenzyme. As mentioned previously, $\mathrm{MgCl}_{2}$ and $\mathrm{CoSO}_{4}$ have a remarkable activating effect, whereas $\mathrm{MnCl}_{2}$ shows a slight inhibitory effect on enzyme activity $^{36}$. Candida albicans ADA is inhibited by 1-methyl adenosine, AMP, $p$-chloromercuribenzoate, $p$-hydroxymercuribenzoic acid and theophylline ${ }^{39}$. ADA from Argopecten irradians concentricus has been found sensitive to these inhibitors: 2'-deoxyinosine, 2-amino-4-hydroxypteridine, folic acid, hypoxanthine, inosine, $p$-chloromercuribenzoate and purine riboside ${ }^{38}$. The enzymatic reaction of Nocardioides 
sp. ADA is potently inhibited by $\mathrm{Hg}^{2+}, \mathrm{Ag}^{2+}, \mathrm{Cd}^{2+}, \mathrm{Mg}^{2+}$, $\mathrm{Mn}^{2+}, \mathrm{Zn}^{2+}, o$-phenanthroline and pentachlorophenol, and noticeably inhibited by 8-bromoadenosine, theobromine and theophylline ${ }^{31}$. Klebsiella sp. ADA is also inhibited by metal ions $\left(\mathrm{Fe}^{2+}, \mathrm{Hg}^{2+}, \mathrm{Ni}^{2+}, \mathrm{Zn}^{2+}\right)^{29}$. Other microbial ADAs are inhibited by $\mathrm{Hg}^{2+}$, iodoacetamide, iodoacetic acid, $N$-ethylmaleimide, $p$-chloromercuribenzoate, $\mathrm{Pb}^{2+}$, $\mathrm{Zn}^{2+}$ (Micrococcus sodonensis $\left.{ }^{28}\right), \mathrm{Ag}^{+}, \mathrm{Hg}^{2+}$, o-phenanthroline (Streptomyces $\mathrm{sp}^{32}$ ) and $p$-chloromercuribenzoate $\left(\right.$ E. coli $\left.{ }^{25}\right)$. Plasmodium falciparum ADA activity is blocked by 2,6-diaminopurine, 6-methylamino riboside, 6-methylmercaptopurine riboside, adenine and cordycepin ${ }^{43}$.

In case of Homo sapiens adenosine deaminase, binding of 1,6-dihydro-6-(hydroxymethyl)purine riboside and coformycin causes changes in the protein conformation. Both human ADA1 and chicken (Gallus gallus) ADA1 show similar substrate specificity and sensitivity to the inhibitors 2'-deoxycoformycin and erythro-9-(2-hydroxy3-nonyl)-adenine hydrochloride ${ }^{26}$. On the other hand, ADA2 from chicken is not inhibited by erythro-9-(2-hydroxy-3-nonyl)-adenine hydrochloride ${ }^{44}$.

Other inhibitors of human ADA include 2-aminopurine, adenine, guanosine, inosine, $\mathrm{Cu}^{2+}, \mathrm{Hg}^{2+}$, and $p$-chloromercuryphenylsulfonate ${ }^{45}, 2,6$-diaminopurine, 6 methylamino riboside, 6-methylmercaptopurine riboside, cordycepin, deoxycoformycin, erythro-9-(2-hydroxy-3nonyl)adenine ${ }^{43}, 2,6$-diaminopurine sulfate, 4-amino-5-imidazole carboxamide hydrochloride, 4-amino-5-imidazole carboxyamide ribonucleoside, 6-chloropurine, and iodopurine $^{46}$.

Purine riboside was a competitive inhibitor of Mus musculus ADA, whereas 2'-3'-o-isopropylidene adenosine acted as an uncompetitive inhibitor. The enzyme activity was also inhibited by theophylline ( $40 \%$ loss of the original activity), caffeine (30\%), L-cysteine (50\%) and strongly by $\mathrm{Hg}^{2+}(98 \%)$. In addition, purine analogs such as inosine, purine, alpha-adenosine and adenine showed variable inhibition effects. ADA activity towards 3'-deoxyadenosine and 6-chloropurine riboside decreased to $70 \%$ and $60 \%$ of the original value, respectively. However, the activity with 2'-o-methyl adenosine increased by $30 \%$ comparing to the activity obtained with adenosine ${ }^{40}$.

ADA from bovine spleen (Bos taurus) is inhibited by erythro-9-(2-hydroxy-3-nonyl)adenine, erythro-9-(2-hydroxy-3-nonyl)-3-deazaadenine ${ }^{47}, 9-(p-$ aminobenzyl)adenine, $p$-chloromercuribenzoate and purine riboside ${ }^{41}$.

Another known mammalian ADA from Camelus dromedaries is inhibited by $\mathrm{Mg}^{2+}, \mathrm{Mn}^{2+}$ and purine riboside ${ }^{42}$.

As a part of a program to explore structure-activity relationships for extremely tight binding of coformycin inhibitors to adenosine deaminase, a series of analogues containing the imidazo[ $4,5-\mathrm{e}][1,2,4]$ triazepine ring system was synthesized and showed to display inhibitory properties towards mammalian ADA in in vitro tests ${ }^{48}$.

\subsection{Genetic relationship and structures of adenosine deami- nases}

Human ADA1 gene is located on the chromosome 20 (20q12-q13.11). The gene is $32,213 \mathrm{bp}$ long and contains
A.
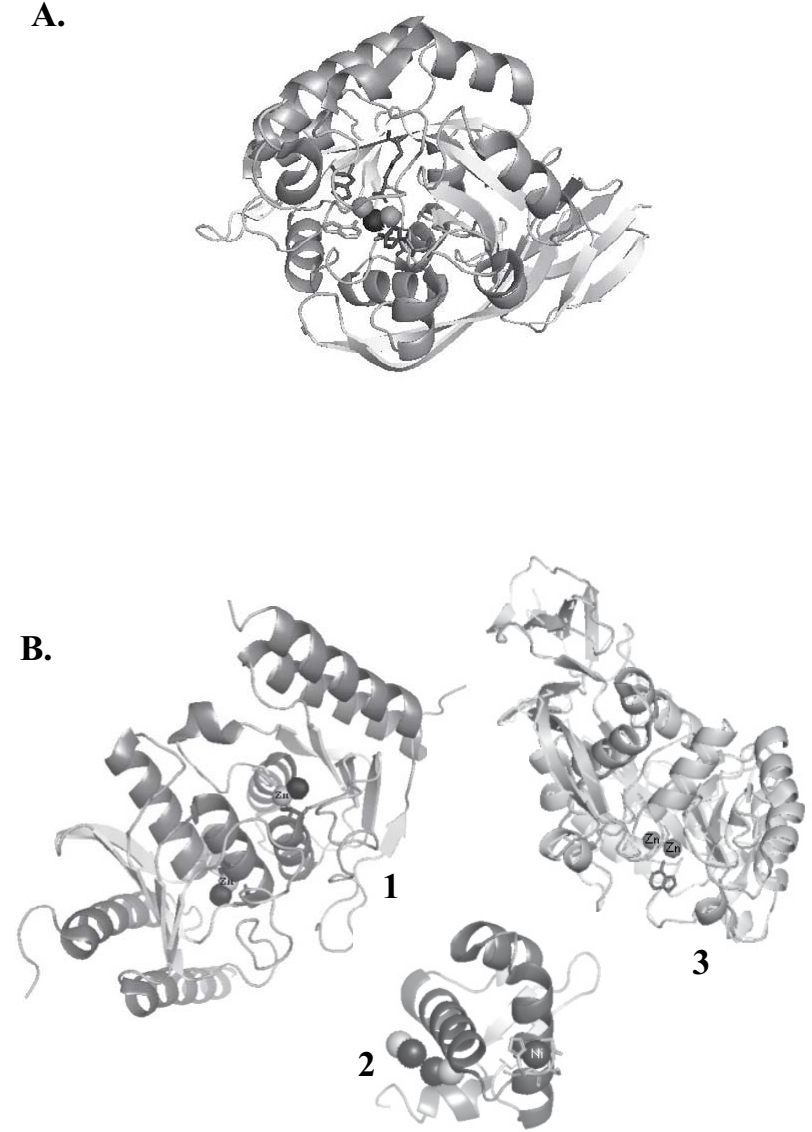

Fig. 2. Structures of adenine and adenosine deaminases: A. Adenine deaminase from Enterococcus faecalis (PDB entry 2ICS) obtained as recombinant protein from E. coli $i^{3}$, B. Adenosine deaminases - 1) whole structure of ADAT from Escherichia coli (PDB entry 1Z3A), 2) Z- $\beta$ domain of ADAR1 from Homo sapiens (PDB entry 1XMK), 3) whole structure of ADA from Bos taurus (PDB entry 1VFL). The structural coordinates were visualized with Open-Source PyMOL 0.99rc2 (DeLano Scientific LLC, Palo Alto, CA, USA).

11 introns, the coding sequences being only $4,53 \%$ of the whole gene. The encoded protein belongs to the metallodependent hydrolase superfamily, adenosine deaminase (ADA) family and contains adenosine deaminase (ADA) conserved domain cd01320.

Typical prokaryotic gene representative, ADA gene from Escherichia coli $\mathrm{K} 12$, is located in the position from 1700257 to 1701258 of the genome (1001 bp). The encoded enzyme contains the same conserved domain as a human ADA.

Protein structures have been solved for prokaryotic and eukaryotic ADAs, a variety of domains and chains of ADAR, and for four chains of bacterial ADAT. No structure of a plant enzyme of this class is known. Comparison of protein structures of three typical representatives of these enzymes is shown in Fig. 2B. 
A.

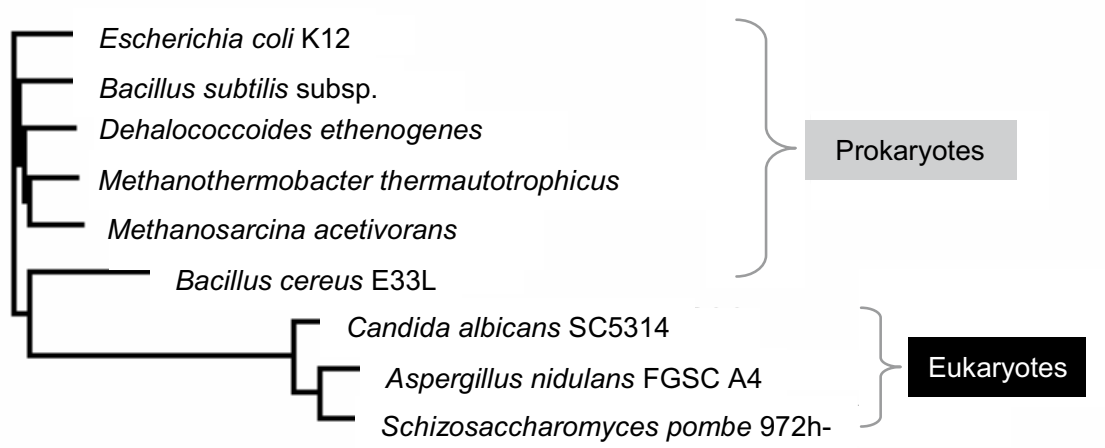

B.

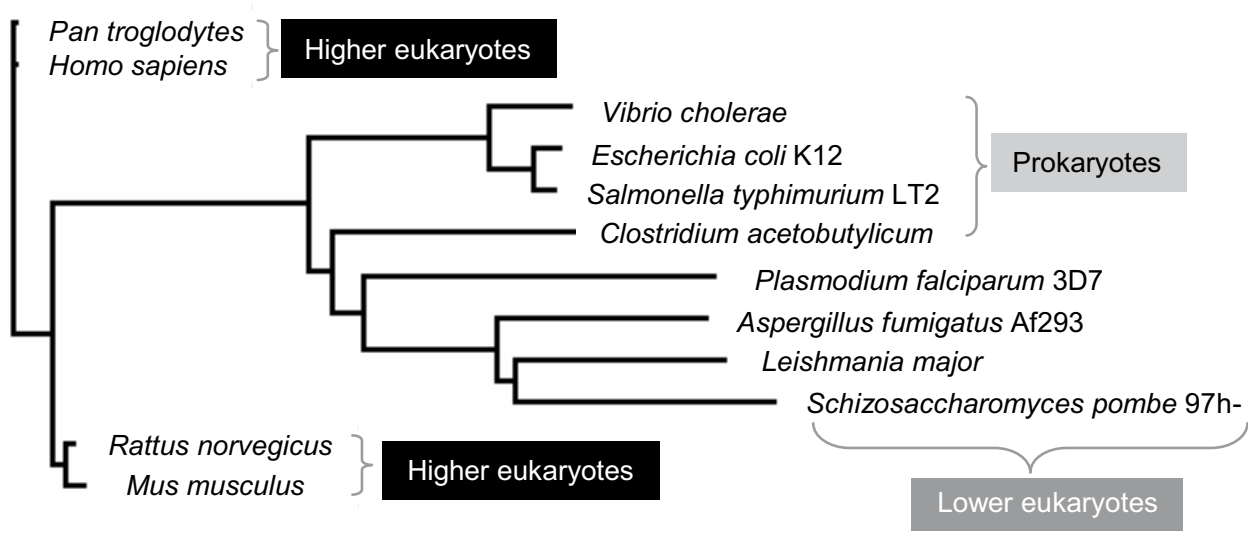

Fig. 3. Fitch phylogenetic unrooted tree (Phylogram) of adenine or adenosine deaminases. The analysis was done with the software BioEdit software 7.0.5.360 and TreeView 1.6.6 (http://taxonomy.zoology.gla.ac.uk/rod/rod. html): A. Bacterial, archaeal and fungal ADEs, B. Prokaryotic and eukaryotic adenosine deaminases.

Sequences of adenosine deaminase coding genes of prokaryotes and eukaryotes are more related each other than those of adenine deaminases. The sequences of the genes from higher eukaryotes, mammalians particularly, are almost identical. At protein level, the degree of identity among mammalian enzymes is very high and clearly separates this group from the others (Tab. 2). The same relationship is shown in the phylogenetic tree (Fig. 3B). Noticeably, fungal enzymes form group, which is the least similar with the others. Although these enzymes are annotated as ADAs, there is actually no experimental evidence that the respective proteins show ADA-like activity. Contradictory to the annotation, the enzyme from Schizosaccharomyces pombe (SPBC1198.02) shows no activity with adenosine, but readily acts on adenine ${ }^{2,54}$, thus being ADE not ADA. It is likely that also other closely related enzymes from Ascomycetes possess ADE, but not ADA activity and maybe adenosine deaminases are not presented in lower eukaryotes at all.

These genes from lower eukaryotes contain no introns, but introns occupy about $95 \%$ of the DNA sequence in mammalian ADA genes. Typically, the ADA gene has 11 introns. Dog ADA gene contains an additional $40 \mathrm{bp}$ intron that may have evolved by an excision from the 5'- part of the $9^{\text {th }}$ intron. Mammalian ADA genes range from 23,593 bp (mouse) to 33,391 bp (chimpanzee). The most significant intron sequence similarity is between human and chimpanzee and then between mouse and rat, where the introns 5, 7, and 11 are the most conserved.

\subsection{Adenosine deaminases in plants - an open question}

Despite the adenosine deaminase enzymes have been thoroughly described in prokaryotes, lower eukaryotes and mammals, there are only scarce reports on these enzymes in plants. Although completed genome databases of Arabidopsis thaliana and other plants show presence of putative encoding genes, the corresponding proteins have not been obtained so far nor the activity towards adenosine demonstrated. Some articles even speculate that adenosine deaminase is not present at all in plant tissue $^{49,50,51}$ or that enzyme activity is too low and the main enzyme for adenosine recycling in plants is adenosine kinase (EC 2.7.1.77) $)^{52,53}$.

The corresponding hypothetical plant gene product contains an adenosine/AMP conserved domain cd00443 (different from cd01320 present in other ADAs) that is also present in some prokaryotic and eukaryotic enzymes annotated as ADA, adenosine/AMP deaminase or ADA- 
like proteins. On amino acid sequence level, putative plant enzymes show close relationship between each other, while they differ from ADAs of other origin, especially from those of microorganisms (Tab. 3).

\section{CONCLUSIONS}

Nowadays, the study of adenine/adenosine deaminases is receiving raising attention. Several active recombinant enzymes from microorganisms were prepared so far, such as ADEs from Escherichia coli ${ }^{7}$, Enterococcus faecalis $^{3}$, Saccharomyces cerevisiase ${ }^{54}$ and Schizosaccharomyces pombe $^{54}$. These proteins have been produced mainly for biochemical and structural studies, but there is also a possible in vitro application of the recombinant proteins, i.e. in analytical chemistry. Development of a biosensor for the assay of adenine in biological fluids that is based on adenine deaminase/xanthine oxidase/peroxidase system is in progress (Petr J, Pospíšilová H, Frébort I, Nistor M, unpublished results).

Human adenosine deaminase is very intensively investigated at the medical field because of diseases induced by lack or excess of its activity. Acquired knowledge is then used in attempting to therapy the adenosine deaminasesbased illness. For examples, enzyme replacement therapy, using red blood cells as a source of encapsulated human ADA, restored both $T$ and $B$ cell function of patients with adenosine deaminase deficient form of severe combined immunodeficiency (SCID) $)^{55}$ and hematopoietic stem cell gene therapy led to the successful reconstitution of immune function in a child who showed a poor response to PEG-ADA enzyme replacement ${ }^{56}$. ADA deficiency was selected for the first approved human gene therapy trial $^{57}$. Determination of ADA could be used as a nonspecific marker of T-lymphocyte activation ${ }^{58}$. As a model system for human therapy, mouse is often used also in the investigation of ADA-linked disorders. Hence, murine ADA was cloned and expressed in modified $E$. coli and monolayer cultures of murine Cl-1D LM (thymidine kinase $^{-}$) fibroblast cells derived from bone marrow stromal cells of a $(\mathrm{C} 57 \mathrm{BL} / 6 \mathrm{~J} \times \mathrm{C} 3 \mathrm{H} / \mathrm{HeJ}) \mathrm{F}_{1}$ mouse and human embryonic kidney (HEK) 293 cells $^{59}$.

\section{ACKNOWLEDGEMENTS}

This work was supported by the grants 522/06/0022 from the Czech Science Foundation and MSM6198959216 from the Ministry of Education, Youth and Physical Education, Czech Republic. Authors thank Václav Mik for help with protein structure visualizations.

\section{REFERENCES}

1. Murray AW. The biological significance of purine salvage. Annu Rev Biochem 1971; 40:811-26.

2. Ribard C, Rochet M, Labedan B, Daignan-Fornier B, Alzari P Scazzocchio $\mathrm{C}$ et al. Sub-families of of $\alpha / \beta$ barrel enzymes: a new adenine deaminase family. J Mol Biol 2003; 334:1117-31.
3. Sugadev R, Kumaran D, Burley SK, Swaminathan S. Crystal structure of an adenine deaminase. New York Structural Genomics Research Consortium (Nysgrc), 2006/9/13 (PDB accession 2ICS).

4. Jun HK, Sakai T. Some properties of adenine deaminase of Pseudomonas synxantha. J Ferment Technol 1979; 57:294-9.

5. Nygaard P, Duckert P, Saxild HH. Role of adenine deaminase in purine salvage and nitrogen metabolism and characterisation of the ade gene in Bacillus subtilis. J Bacteriol 1996; 178:846-53.

6. Kidder GW, Nolan LL. Adenine aminohydrolase: occurrence and possible significance in trypanosomid flagellates. Proc Natl Acad Sci USA 1979; 76:3670-2.

7. Matsui H, Shimaoka M, Kawasaki H, Takenaka Y, Kurahashi O. Adenine deaminase activity of the yicP gene product of Escherichia coli. Biosci Biotechnol Biochem 2001; 65:1112-8.

8. Heppel LA, Hurwitz J, Horecker BL. Adenine deaminase of Azobacter vinelandii. J Am Chem Soc 1957; 79:630-3.

9. Kidder GW, Dewey VC, Nolan LL. Adenine deaminase of a eukaryotic animal cell, Crithidia fasciculata. Arch Biochem Biophys 1977; 183:7-12.

10. Sakai T, Jun HK. Purification and characterisation of adenine deaminase in Pseudomonas synxantha. J Ferment Technol 1978; 56:257-65.

11. Deeley MC. Adenine deaminase and adenine utilization in Saccharomyces cerevisiae. J Bacteriol 1992; 174:3102-10.

12. Dorgan KM, Wooderchak WL, Wynn DP, Karschner EL, Alfaro $\mathrm{JF}$, Cui Y et al. An enzyme-coupled continuous spectrophotometric assay for S-adenosylmethionine-dependent methyltransferases. Anal Biochem 2006; 350:249-55.

13. Allam AM, Elawamry ZA, Elzainy TA. Discrete activities for adenine and adenosine deaminations in extracts of Streptomyces viridiviolaceus. Egypt J Bot 1981; 24:149-52.

14. Abbondandolo A, Weyer A, Heslot H, Lambert M. Study of adenine aminohydrolase in the yeast, Schizosaccharomyces pombe. J Bacteriol 1971; 108:959-63.

15. Wolf J, Gerber AP and Keller W. tadA, an essential tRNA-specific adenosine deaminase from Escherichia coli. EMBO J 2002; 21:3841-51.

16. Hirschhorn R, Ratech H. Isozymes of adenosine deaminase. In: Ratazzi MC, Scandalia JG, Whitt GS, editors. Current topics in biological and medical research, vol. 1. New York: Alan R. Liss; 1980. p. 132-57.

17. Maier SA, Galellis JR, McDermid HE. Phylogenetic analysis reveals a novel protein family closely related to adenosine deaminase. J Mol Evol 2005; 61:776-94.

18. Zavialov AV and Engström A. Human ADA2 belongs to a new family of growth factors with adenosine deaminase activity. Biochem $\mathbf{J}$ 2005; 391:51-7.

19. Van der Weyden MB, Kelley WN. Human adenosine deaminase. Distribution and properties. J Biol Chem 1976; 251:5448-56.

20. Aronow BJ, Silbiger RN, Dusing MR, Stock JL, Yager KL, Potter $\mathrm{SS}$, et al. Functional analysis of the human adenosine deaminase gene thymic regulatory region and its ability to generate positionindependent transgene expression. Mol Cell Biol 1992; 12:417085.

21. Dusing MR, Wiginton DA. Sp1 is essential for both enhancermediated and basal activation of the TATA-less human adenosine deaminase promoter. Nucleic Acids Res 1994; 22:669-77.

22. Xie W, Duan R, Safe S. Estrogen induces adenosine deaminase gene expression in MCF-7 human breast cancer cells: role of estrogen receptor-Sp1 interactions. Endocrinology 1999; 140:219-27.

23. Keegan LP, Leroy A, Sproul D and O'Connell MA. Adenosine deaminases acting on RNA (ADARs): RNA-editing enzymes. Genome Biol 2004; 5:209.

24. Ataie G, Safarian S, Divsalar A, Saboury AA, Moosavi-Movahedi AA, Ranjbar B, et al. Kinetic and structural analysis of the inhibition of adenosine deaminase by acetaminophen. J Enzyme Inhib Med. Chem 2004; 19:71-8.

25. Nygaard P. Adenosine deaminase from Escherichia coli. Methods Enzymol 1978; 51:508-12. 
26. Iwaki-Egawa S, Watanabe Y. Characterization and purification of adenosine deaminase 1 from human and chicken liver. Comp Biochem Physiol B Biochem Mol Biol 2002; 133:173-82

27. Tsukada T, Yoshino M. Adenosine deaminase from Azotobacter vinelandii. Purification and properties. Arch Microbiol 1980; 128:228-32.

28. Pickard MA. Purification and some properties of the soluble and membrane-bound adenosine deaminases of Micrococcus sodonensis ATCC 11880 and their distribution within the family Micrococcacea. Can J Biochem 1975; 53:344-53.

29. Ling F, Inoue Y, Kimura A. Purification and characterization of adenosine deaminase from Klebsiella sp. LF 1202. J Ferment Bioeng 1991; 71:89-92.

30. Rosinová M, Zelinková E, Zelinka J. (1978) Adenosine aminohydrolase from Streptomyces aureofaciens. Collect Czech Chem Commun 1978; 43:2324-9.

31. Jun HK, Kim TS, Yeeh Y. Purification and characterization of an extracellular adenosine deaminase from Nocardioides sp. J-326TK Biotechnol Appl Biochem 1994; 20:265-77.

32. Jun HK, Kim TS, Sakai T. Purification and characterization of extracellular adenosine deaminase from a Streptomyces sp. J Ferment Bioeng 1991; 71:6-11.

33. Hough RF, Bass BL. Purification of the Xenopus laevis doublestranded RNA adenosine deaminase. J Biol Chem 1994; 269:99339.

34. Keegan LP, Gerber AP, Brindle J, Leemans R, Gallo A, Keller $\mathrm{W}$ et al. The properties of a tRNA-specific adenosine deaminase from Drosophila melanogaster support an evolutionary link between pre-mRNA editing and tRNA modification. Mol Cell Biol 2000; 20:825-33.

35. Lupidi G, Marmocchi F, Cristalli G. Inhibition studies on membrane adenosine deaminase from human placenta. Biochem Mol Biol Int 1998; 46:1071-80.

36. Abu-Shady MR, Elshafei AM, el-Beih FM, Mohamed LA. Properties of adenosine deaminase in extracts of Aspergillus terricola. Acta Microbiol Pol 1994; 43:305-11.

37. Gabellieri E, Bernini S, Piras L, Cioni P, Balestreri E, Cercignani G et al. Purification, stability and kinetic properties of highly purified adenosine deaminase from Bacillus cereus NCIB 8122. Biochim Biophys Acta 1986; 884:490-6.

38. Harbison GR, Fisher JR. Purification, properties and temperature dependence of the adenosine deaminase from a poikilotherm (Bay scallop). Arch Biochem Biophys 1973; 154:81-95.

39. Challa A, Johnson S, Robertson K, Gunasekaran M. Properties of adenosine deaminase from Candida albicans. J Basic Microbiol 1999; 39:97-101.

40. Singh LS, Sharma R. Purification and characterization of intestinal adenosine deaminase from mice. Mol Cell Biochem 2000; 204:127-34

41. Rossi CA, Lucacchini A. Purification and some properties of calf thymus adenosine deaminase. Biochem Soc Trans 1974; 2:1313-5.

42. Alrokayan S. Purification and characterization of adenosine deaminase from camel skeletal muscle. Int J Biochem Cell Biol 2002; 34:1608-18

43. Daddona PE, Wiesmann WP, Lambros C, Kelley WN, Webster HK Human malaria parasite adenosine deaminase. Characterization in host enzyme-deficient erythrocyte culture. J Biol Chem 1984; 259:1472-5.

44. Iwaki-Egawa S, Namiki C, Watanabe Y. Adenosine deaminase 2 from chicken liver: purification, characterization, and N-terminal amino acid sequence. Comp Biochem Physiol B Biochem Mol Biol 2004; 137:247-54.

45. Akedo H, Nishihara H, Shinkai K, Komatsu K, Ishikawa S. Multiple forms of human adenosine deaminase. I. Purification and characterization of two molecular species. Biochim Biophys Acta 1972; 276:257-71.

46. Agarwal RP, Parks RE. Adenosine deaminase from human erythrocytes. Methods Enzymol 1978; 67:502-7.

47. Mardanyan SS, Sharoyan SG, Antonyan AA, Lupidi G, Cristalli $\mathrm{G}$. Interaction of adenosine deaminase with inhibitors. Chemical modification by diethyl pyrocarbonate. Biochemistry (Mosc). 2002; 67:770-7.

48. Reayi A, Hosmane RS. Inhibition of adenosine deaminase by novel 5:7 fused heterocycles containing the imidazo [4,5-e][1,2,4]triazepine ring system: a structure-activity relationship study. J Med Chem 2004; 47:1044-50.

49. Yabuki N, Ashihara H. Catabolism of adenine nucleotides in suspension-cultured plant cells. Biochim Biophys Acta 1991; 1073:474-80

50. Katahira R, Ashihara H. Profiles of purine biosynthesis, salvage and degradation in disks of potato (Solanum tuberosum L.) tubers. Planta 2006; 225:115-26

51. Guranowski A. Purine Catabolism in Plants. Plant Physiol 1982; 70:344-9

52. Moffatt BA, Stevens YY, Allen MS, Snider JD, Pereira LA, Todorova MI et al. Adenosine kinase deficiency is associated with developmental abnormalities and reduced transmethylation. Plant Physiol 2002; 128:812-21.

53. Moffatt BA, Ashihara H. Purine and pyrimidine nucleotide synthesis and metabolism. In: Somerville CR, Meyerowitz EM, editors. The Arabidopsis Book. Rockville, MD: American Society of Plant Biologists; 2002 (April 4), doi: 10.1199/tab.0018. Available from: http://www.aspb.org/publications/arabidopsis/

54. Pospíšilová H, Novák O, Frébortová J, Strnad M, Frébort I Oxidative and hydrolytic cleavage of cytokinin derivatives with biomedical and biotechnological potential. In: Abstracts of International Symposium of Fifth 21st Century COE "Towards Creating New Industries Based on Inter-Nanoscience”. 2006, December 8-9, Awaji, Japan; p. 15-20.

55. Polmae SH. Enzyme replacement and other biochemical approaches to the therapy of adenosine deaminase deficiency. Ciba Found Symp 1978; 68:213-30.

56. Gaspar HB, Bjorkegren E, Parsley K, Gilmour KC, King D, Sinclair $\mathrm{J}$ et al. Successful reconstitution of immunity in ADA-SCID by stem cell gene therapy following cessation of PEG-ADA and use of mild preconditioning. Mol Ther 2006; 14:505-13.

57. Blaese RM, Culver KW, Miller AD, Carter CS, Fleisher T, Clerici $\mathrm{M}$ et al. T lymphocyte-directed gene therapy for ADA- SCID: initial trial results after 4 years. Science 1995; 270:475-80.

58. Calis M, Ates F, Yazici C, Kose K, Kirnap M, Demir M et al. Adenosine deaminase enzyme levels, their relation with disease activity, and the effect of colchicine on adenosine deaminase levels in patients with Behcet's disease. Rheumatol Int 2005; 25:452-6.

59. Hsu LCh, Liu S, Abedinpour F, Beech RD, Lahti JM, Kidd VJ et al. The murine $\mathrm{G}+\mathrm{C}$-rich promoter binding protein $\mathrm{mGPBP}$ is required for promoter-specific transcription. Mol Cell Biol 2003; 23:8773-85.

60. Hall TA. BioEdit: a user-friendly biological sequence alignment editor and analysis program for Windows 95/98/NT. Nucl Acids Symp Ser 1999; 41:95-8. 